\title{
Empirical study of the National Health Service in U.K. and the U.S. Medical Care System
}

\author{
Kai Xie \\ University of Southampton \\ University Rd, Southampton \\ Hampshire SO17 1BJ \\ United Kingdom
}

Tel: +44-0-758-7188-656Ｅ-mail: apoloxie@gmail.com

Received: October 17, $2011 \quad$ Accepted: November 15, $2011 \quad$ Published: January 5, 2012

doi:10.5430/ijfr.v3n1p33 URL: http://dx.doi.org/10.5430/ijfr.v3n1p33

\begin{abstract}
This paper presents a feasibility study of the mechanism of the National Health Services in U.K and the U.S. Medical Care System respectively. The issue is empirically examined from four aspects namely externalities, information asymmetry, and market failure. It comes to the conclusion that with the practical guidance of the government intervention, it is possible to cope with the agency problems with high efficiency.
\end{abstract}

Keywords: Externalities, Asymmetric Information, Government Regulations, NHS, Medical Care, U.S.

In free competition, the resources can be allocated efficiently in the market for most commodities. However, such competition in the health care market can lead to ethic issues and inefficiency. This report, through our research, is aimed at stating the situation that market failure can be attributed to the following reasons and examining how both countries, U.K. and U.S., respond to such flaws.

Externalities

Externalities are present whenever some economic agent's welfare (utility or profit) is 'directly' affected by the action of another agent in the economy (Jean H. and Gareth D.M., 2004). In certain health care, people can benefit from others' consumption, which will cause the social marginal benefit of health care to be higher than the individual. Subsequently, the problem of underproduction will arise.

Adverse selection and moral hazard in the health insurance market

Health care is significantly different from common commodities such as food and clothes, since we don't know when and how much we need pay. Heath insurance makes people better off by reducing the uncertainties.

Problems specifically adverse selection and moral hazard inevitably exist in the market. Adverse selection is caused by the asymmetric information between the insurance company and the consumers, inducing high insurance fees. Worse, people in low risk will be driven out of the market.

Another problem is the moral hazard. When people have insurance, they tend to be less careful about their health status increasing their demands of the health care service.

The patients with insurance will demand more health care resources than they actually need, which will cause a welfare loss.

$<$ Figure 1 about here $>$

In Figure 1, we assume that marginal cost is constant. The amount of health care that should be provided is $\mathrm{Q}_{1}$, where marginal cost equal to marginal benefit. However, because of the excess demand of patients $\mathrm{Q}_{2}$ will be provided, the shaded area represents welfare loss.

The information asymmetry between patient and doctor: agent problem

In health care market, the relationship between the doctor and patient is much different from the normal buyers and sellers. The patient is there to give the doctor all the information the doctor needs in order that the doctor can make a 
decision, and the patient should then implement that decision once the doctor has made it. (Chrnew \& Michael 2010) As a result, patients' consumption largely depends on the doctor. Therefore doctors have an incentive to make patient consume more in order to make more profit, which we call agent problem. Hence overproduction occurs.

\section{Monopoly}

Certain hospitals in some areas can easily achieve local monopoly. Firstly, People in one community may have only one choice of the hospital or doctor because others are far away. Secondly it is the natural monopoly. Because of the conflict between the high fixed cost and the confined demands, only one hospital can make profit. (Hodgson Geoffrey 2009)

\section{The U.K. Market}

For health care, the resource cannot be allocated efficiently in the free market. Government interventions play an essential role in providing the health care. The UK government established NHS providing the public with the health care. Let's check how NHS solves the flaws listed below.

Monopoly power of hospital:

Before making the purchasing decisions, buyers always want to compare between goods and service provider with different calibrations. Since free market will induce the complicated management, which have little relationship with the opportunity cost, government will pull the free-market price, with the mandatory power, to the more preferable price where price equals average cost, at which point, the pricing behaviour finally gain more consumer surplus.(Caro J. 2010)

$<$ Figure 2 about here $>$

If the health service market is in the state of monopoly, in order to realize maximization of the profit, the monopolist will choose the point $\mathrm{M}\left(\mathrm{Q}_{1}, \mathrm{P}_{1}\right)$ in which consumer surplus is triangle $\mathrm{AP}_{1} \mathrm{M}$. Government intervention would drag the production point from $\mathrm{M}\left(\mathrm{Q}_{1} \mathrm{P}_{1}\right)$ to $\mathrm{C}\left(\mathrm{Q}_{2}, \mathrm{P}_{2}\right)$, where the consumer surplus triangle $\mathrm{ACP}_{2}$ becomes larger than the previous one.

\subsection{Externality}

As shown in figure 3 , it is assumed that the marginal cost is constant. $\mathrm{L}_{2}$ represents the individual marginal benefit, $\mathrm{L}_{1}$ the marginal benefit of the others people, and $\mathrm{L}_{3}$ the social marginal benefit namely the sum of $\mathrm{L}_{1}$ and $\mathrm{L}_{2}$. People will consume at point $\mathrm{A}$. Then the social optimal point is $\mathrm{B}$, where social marginal benefit is equal to marginal cost. However, in UK, budget constrain determines the quantity of resources available for the NHS, explicitly setting the maximum amount of health care available to NHS patients as a whole (Martin G. 2003). If the NHS has the exact information, they will give appropriate budgets to provide health care at $\mathrm{B}$, which can solve externalities easily.

$<$ Figure 3 about here $>$

\subsection{Excess Demand due to Moral Hazard}

In insurance-based health care systems, the problem of potential 'excess' demand exists because of moral hazard, which has consumer side and supply side (Chrnew \& Michael 2010). Because the cost of treatment is almost zero, people in NHS system would require further and better treatments to make them healthier though they were not that unhealthy. The NHS system solves the problem, using the method that doctors decide who needs treatment. NHS is a system classified and the first level is GP. Particularly, GPs act as both a guidance (to the appropriate specialist) and as a filter. In other words, patient would not be able to have further treatment without the permission of his GP. This helps overcome the problems of consumer ignorance and provides a means of controlling the level of demand (Office of Health Economics, 2010).

\subsection{Agent Problem}

In the NHS, all the GPs and doctors are employed by the government. Nevertheless the aims of the hospital are not to make a profit. Doctors will either be under the contract to the NHS or be salaried; they have no financial incentive to induce patients to consume more health care. Additionally, the separation between the doctors' payment and endowment would increasingly overcome the agency problems. (Nigel, 2005)

\subsection{Low Efficiency}

If the government intervenes much more than it should in the situation, the authorities are running the risk of dragging effective motivations down. Because of the mechanism that the doctors will either be under contract to the NHS, doctors in such government-owned institutions needn't worry about making profits. Consequently, hospitals tend to have long waiting queues. Inadequate to cope with the booming amount of the patients' free and partially non-urgent treatment, market will remain in low efficiency. (Chrnew \& Michael 2010) The richer group in society will choose the "private" 
wards. On the other hand, those who had no enough money had to wait in a long queue for their wards at NHS.(Julianle Grand, 1991) Indispensably, low efficiency would influence the quality of the system rendered towards the NHS.

\subsection{Underproduction or Overproduction of Health Care}

Because that the central planner controls the supply of health care through the budget of the NHS, the health care has a risk of underproduction or overproduction. If the central planners were well-informed with the consumers' demand, they will provide as much health care as what can maximize the social optimal. In effect, the asymmetric information between government and patients makes it unlikely to provide the health care at the exact amount.

\section{U.S. Health Care}

The health insurance in US can be divided into two parts, one of which is private insurance consisted of employment-base and direct-purchase insurance, the other by government. The government programs include 9 departments (Note 1) which generally cover the elderly disabled, children, veterans and some of the poor.

\section{$<$ Figure 4 about here $>$}

It's obvious that US government doesn't take over the healthcare market. The government allows the market to allocate resources under a certain system. Our research below deals with how this system copes with the problems existing in free market.

\subsection{Agency Problem and Monopoly Power of the Hospital}

As mentioned above, the agency problem and monopoly power of the hospital will result in market failure. The strict supervision mechanism, however, in America, solves these two problems effectively. Current Procedural Terminology $\left(\mathrm{CPT}{ }^{\circledR}\right)$ is most widely accepted by medical nomenclature used to report medical procedures and services under public and private health insurance programs (American Medical Association, 2010). Doctors use the CPT to record medical services or care they have provided with patients and to send them to the insurance company. To maximize profit, insurance company will spare no efforts to drag down the cost. Consequently, doctors have to give evidence to show that the drugs or services he or she provided are essential. Under such supervision and manipulation, the efficiency will be improved and the agency problem will be solved. Thanks to the existence of CPT, the prices of the health services are uniform all around the country so that hospital cannot use its monopoly power to raise the price of health services. The more service they provide, the more profit hospital will derive.

\subsection{Adverse Selection}

The government in US administrate social insurance namely Medicare, providing insurance for people aged 65 or older, and people of any age with certain disabilities or certain criteria. (Medicare, 2010) With this policy, most people with high risks will be driven out of the health insurance market by the government. This, to some extent, will relieve the adverse selection problem. Subsequently insurance companies would like to provide consumers with different insurance contracts according to some indexes such as age, present health condition etc.

\subsection{Access Demand due to Moral Hazard}

The moral hazard problem of the consumers can be dealt with the managed care which are programs intended to reduce unnecessary health care costs through a variety of mechanisms. When you buy insurance, you would choose a primary care physician in contract with the insurance company. When ill, you would like to see the primary care physician first. If they cannot treat, they will introduce you to specialists who have contract with the same insurance company as well. The primary care physician and specialist both in contract with the insurance company will consider the benefit of insurance companies to deter the excess demand of health care.

\subsection{Equity Problem}

To guarantee the equity of society, the government programs have a very significant role to play. It's acknowledged that in reality a majority group in society involved in the government plan cannot afford the medical fees or the private insurance. Through the program such as Medicare, Medicaid etc, government provides insurance for people who may not able to cover the insurance fees. In private insurance industry, according to the Sec.211 in Affordable Health Care for America Act (U.S. Act, 2010) the insurance company cannot reject the consumer who has already been in bad condition, providing the chance for everyone to get insurance.

However, new problems occur in this system. According to the US Census Bureau, US spent $\$ 2.5$ trillion, $\$ 8,047$ per person, on health care in 2009 covering 17.3\% of the GDP. (US Census Bureau, 2010) Meanwhile, the cost of US health care is ranked the highest in the world. 
From the evidence given by the Organization for Economic Cooperation and Development, OECD, 2008 above, we can safely draw the conclusion that U.S. as a whole pays the most in the world for medical care. Accordingly, reasons behind this particular market behaviour can be argued as follows.

In the US health, prices of the input, for example salaries, medical equipment and so on are more expensive than other countries. So price of the health care will be higher. The hospital can also be less efficient in some ways. That highly fragmented and complex U.S. payment system, for example, requires more administrative personnel in hospitals than would be needed in countries with simpler payment systems (Garerd.F.A. et. Al. May-June 2003)

High pharmaceutical expenditure also is an influential ingredient. Two controversial forces coexist in the U.S. health market: one is the certain private medicine dealers with patents will act as a monopolist (figure 6); Alternatively, Unlike UK which can act as a monopsony(figure 7), the US government, whose power is less influential to intervene the pricing mechanism, can't drag the medicine prices to social optimal point. (Garerd.F.A. et. Al. May-June 2003)

$<$ Figure 5 about here $>$

In Figure 5, without the drug patent, point $\mathrm{A}$ is the equilibrium point under the competitive market because on this point $\mathrm{MC}=\mathrm{MA}$. However, with drug patents, companies will become a monopoly. To maximize the profit, the producer will choose the quantity where $\mathrm{MR}=\mathrm{MC}$ (point $\mathrm{B}$ ). In the chart, the profit will be the rectangle $\mathrm{P}_{1} \mathrm{BCP}$.

$<$ Figure 6 about here $>$

As showed in the Figure 6, in the perfect competitive market, point $\mathrm{A}$ is the equilibrium point where supply equals demand. However, if there is only one buyer (monopsony) in the market, he or she will choose point $\mathrm{B}$ where $\mathrm{MC}=\mathrm{MR}$ to maximize the profit. Then the price of the goods will be dragged down from $\mathrm{P} *$ to $\mathrm{P}_{1}$.

however, it also beneficial because it guarantees that the providers tend to use advanced technology to hold the novel professional patents as monopoly so that they can constrain low cost for high profits. Such behaviour in turn drives the system more efficiently and productively. With profits incentives, U.S. is one of the world leading countries in the realm of medical technological improvement.

\section{Conclusion and Recommendations}

Unexpectedly, government in U.K. plays a dominant role in the health care market. Comparing to U.K., free competition in U.S. is more likely to control the medical market with limited government intervention. Both governments respectively, to tackle with the market failure, adopted different methods, however, new problems for both will occur individually.

For U.K. it seems implausible that a new-build regulatory institution gives the doctors' a comprehensive and objective appraisal to cope with the low-efficiency problem. Specially, a competitive mechanism should be induced to the market emphasizing that the public have the right to choose hospitals freely. Meantime, different hospitals derive the responsive insurance charges based on the amount of patients, forcing the agencies to increase efficiency.

For U.S. windfall tax should be levied from pharmacy and medical device manufacturers, while the government could use this extra amount of funding to compensate consumption of pharmacy. And the government can also take the position of American Medical Association, pricing the services that are recorded by Current Procedural Terminology. It can ensure that the prices are fair and force hospitals work more efficient.

It can therefore be concluded from this report into the differences on the health market both in U.K. and U.S. that the impact of management practices exerted on health care markets in U.K. is inextricably controlled by the government. On the contrary, market power is rather influential in the medical market in U.S. These findings demonstrate that both countries took measurable actions to pursue a more efficient system provided with the public. However, both ingredients are still in consideration for a rather better one.

\section{References}

American Medical Association. (2010). About CPT. [online] Available: http://www.ama-assn.org/ama/pub/physician-resources/solutions-managing-your-practice/coding-billing-insurance/ cpt/about-cpt.shtml

Caro, J. (2010). Efficiency Frontier Approach to Economic Evaluation of Health Care Interventions, Journal of Health Economics 19: 1117-1127. http://dx.doi.org/10.1002/hec.1629

Chrnew \& Michael. (2010). Health Care Spending Growth: Can We Avoid Fiscal Armageddon? Journal of Health Care Organization Provision and Financing 47: 285-295. http://dx.doi.org/10.5034/inquiryjrnl_47.04.285 
Garerd, F. A. et. al. (2003). It's the prices, studied: why the united states is so different from other countries. Health Affair , 22-3

Hodgson, G. (2009). Towards an Alternative Economics of Health Care, Journal of Health Care Economics 4: 99-114

Jean, H. \& Gareth, D. M. (2004). Intermediate Public Economics, $3^{\text {rd }}$, Los Angeles, the MIT Press

Julianle, Grand. (1991). The Theory of Government Failure, British Journal of Political Science 24: 423-442

Martin, G. (2003). The Economics of Health care, $3^{\text {rd }}$, London, LSE Ltd

Medicare. (2010). Medicare Benefit.[online] Available: $\mathrm{http} / / /$ www.medicare.gov/navigation/medicare-basics/medicare-benefits/medicare-benefits-overview.aspx

Nigel, E. (2005). Using market to reform health care, British Medical Journal 331: 1464-1466. http://dx.doi.org/10.1136/bmj.331.7530.1464

Organization for Economic Cooperation and Development, OECD (2008).

Office of Health Economics. (2010). Has the NHS been Successful? [online] Available: http://www.ohe.org/page/knowledge/schools/hc_in_uk/nhs_success.cfm

U.S. Act. (2010). United States Act, Affordable Health Care for America Act, section:211 （2010), [Law]

US Census Bureau. (2010), Income, Poverty, and Health Insurance Coverage in the United States: 2009. [online] Available: http://www.census.gov/prod/2010pubs/p60-238.pdf

\section{Notes}

Note 1. Medicare, Madicaid, State Children's Health Insurance Program, The Veterans Administration, National Institutes of Health, Government run community clinics, Medical Corps of various branches of the military. Certain county and state hospitals

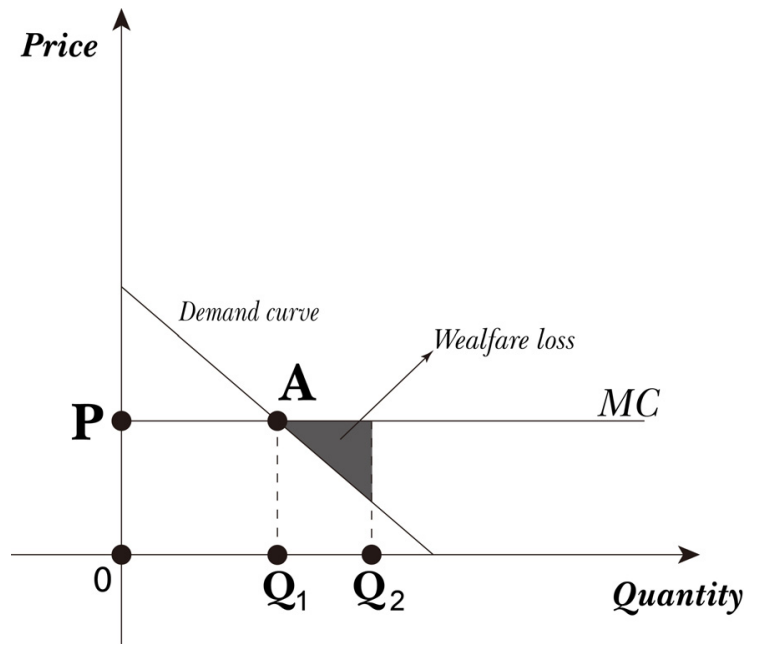

Figure 1. 


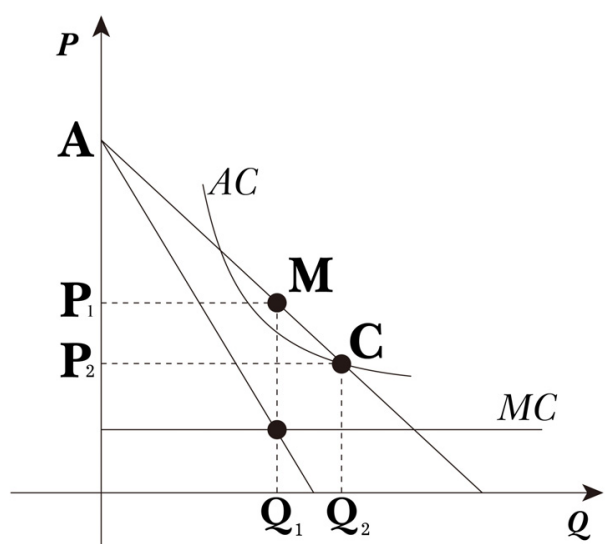

Figure 2.

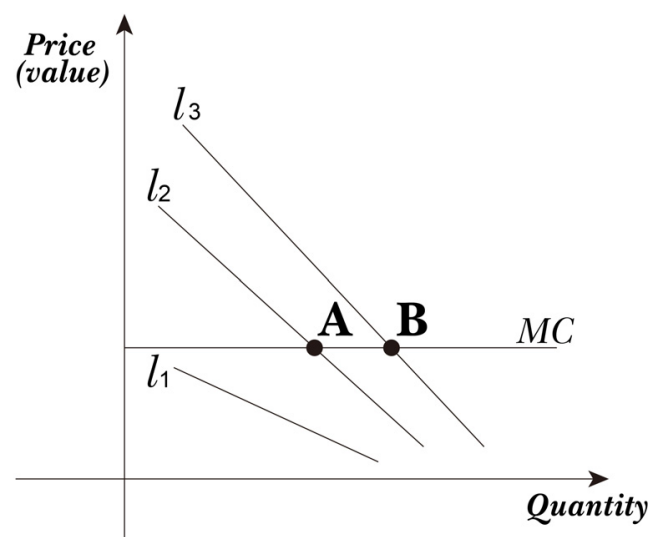

Figure 3.
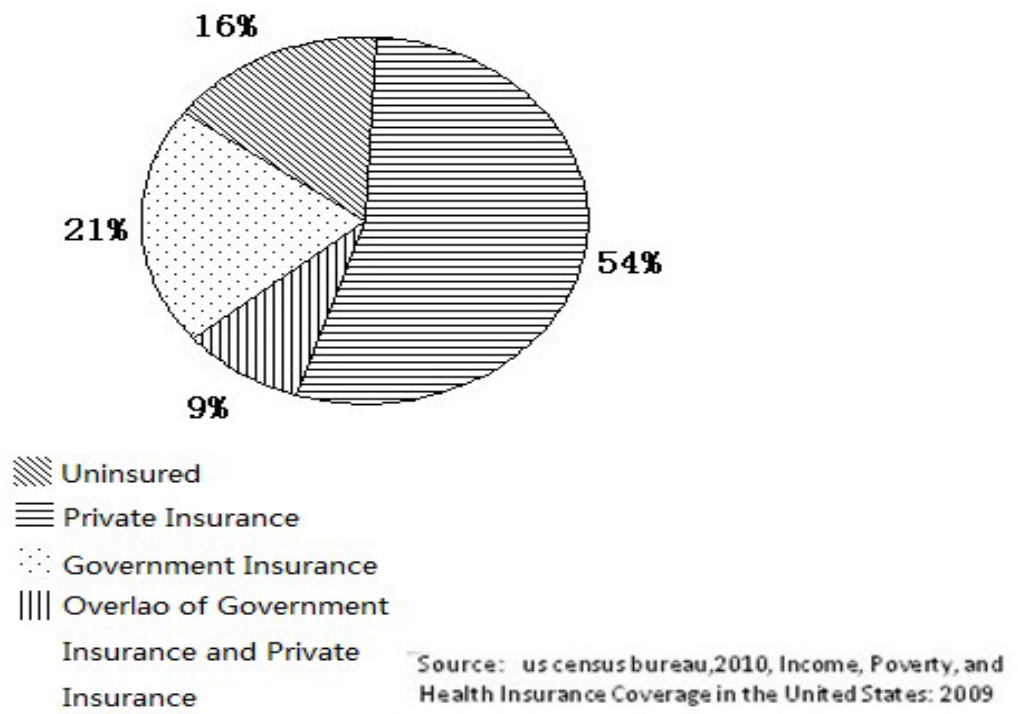

Figure 4. US health insurance status 


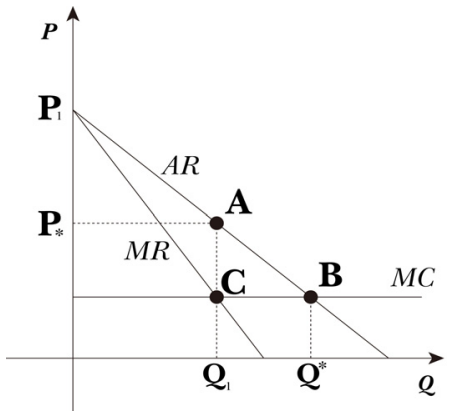

Figure 5.

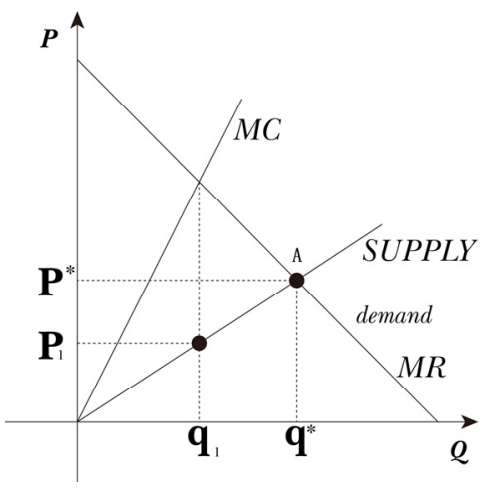

Figure 6. 